This item was submitted to Loughborough's Institutional Repository (https://dspace.lboro.ac.uk/) by the author and is made available under the following Creative Commons Licence conditions.

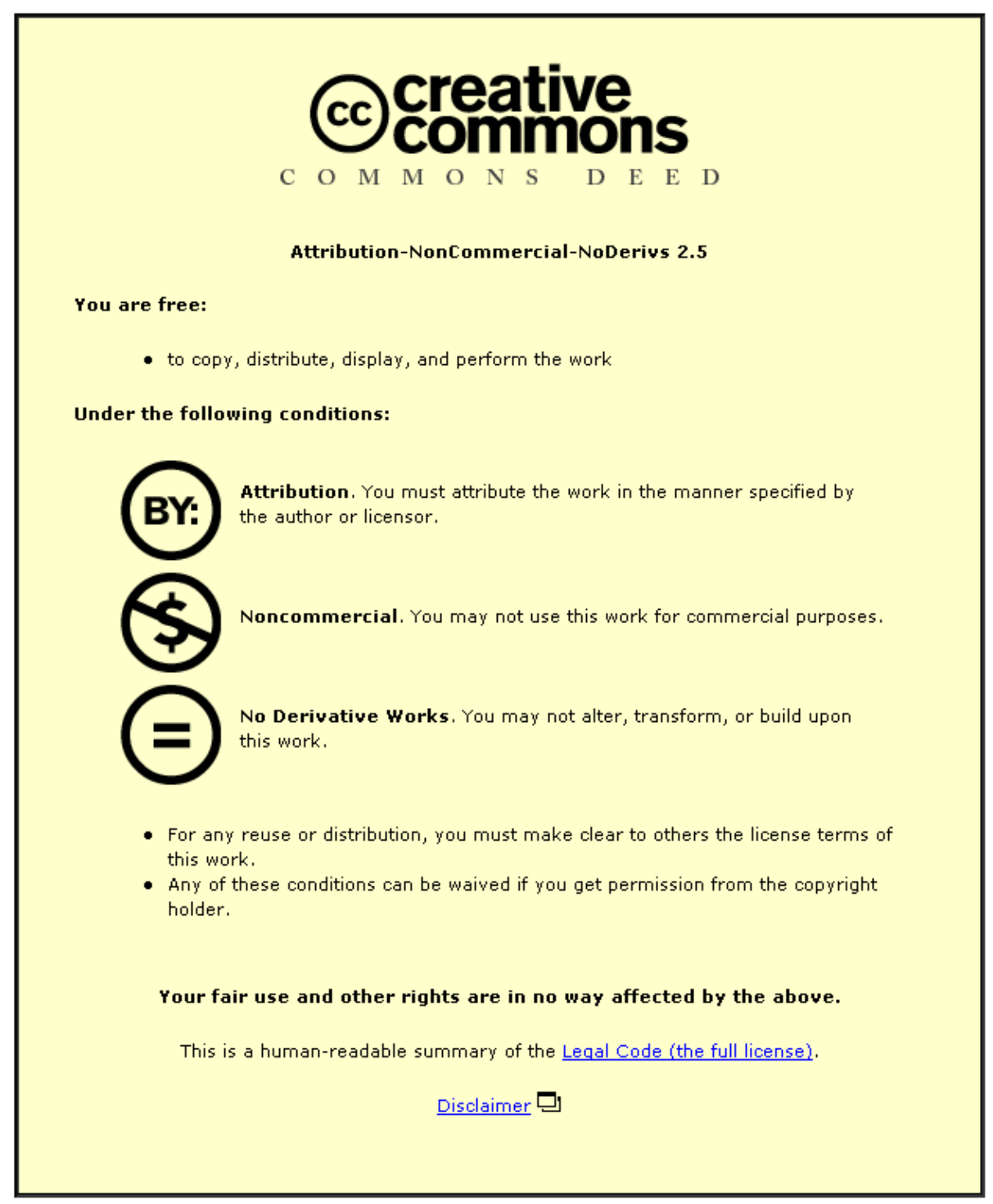

For the full text of this licence, please go to: http://creativecommons.org/licenses/by-nc-nd/2.5/ 


\section{A comparative study of the interfacial reaction between electroless Ni-P coatings and molten tin}

K. Chen ${ }^{1}$, C. Liü ${ }^{2}$, D.C. Whalley ${ }^{2}$ and D.A. Hutt ${ }^{2}$, J.F. Li ${ }^{3}$, and S.H. Mannan ${ }^{3}$,

${ }^{1}$ Research \& Development Department, Macdermid plc, Palmer Street, Bordesley, Birmingham, B9 4EU, UK

${ }^{2}$ Wolfson school of Mechanical and Manufacturing Engineering, Loughborough University, Loughborough, LE11 3TU, UK

${ }^{3}$ Department of Mechanical Engineering, King's College London, Strand, London WC2R 2LS, UK

\section{Abstract}

A comparative study of the reaction characteristics between molten tin and both as-plated and heat-treated Ni-P coatings was carried out, with a specific focus on the stability of the $\mathrm{Ni}_{3} \mathrm{P}$ intermetallic layer and its effects on the subsequent reaction. It was found that a continuous layer of $\mathrm{Ni}_{3} \mathrm{P}$ may be formed on both types of Ni-P during the interfacial reaction, despite the fact that heat-treated Ni-P is a two-phase mixture of $\mathrm{Ni}_{3} \mathrm{P}$ and $\mathrm{Ni}$. The $\mathrm{Ni}_{3} \mathrm{P}$ formed on the heat-treated $\mathrm{Ni}-$ $\mathrm{P}$ was thinner than that on as-plated Ni-P. A mass conservation analysis of $\mathrm{P}$ revealed that no or limited $\mathrm{P}$ was lost into the molten tin when the $\mathrm{Ni}_{3} \mathrm{P}$ layer was thin, whereas a significant loss of $\mathrm{P}$ took place as the $\mathrm{Ni}_{3} \mathrm{P}$ thickness increased. It is proposed that the $\mathrm{Ni}_{3} \mathrm{P}$ phase is stable and it may not undergo chemical decomposition during the interfacial reaction. The loss of $P$ to the molten tin observed in the present study is most likely due to the crumbling of $\mathrm{Ni}_{3} \mathrm{P}$ particles into the liquid phase, as a result of the enhanced mass transport due to use of thin copper wire substrates rather than a planar surface. Finally, the results show that the $\mathrm{Ni}_{3} \mathrm{P}$ phase cannot act 
as an effective barrier layer to the attack of molten tin toward the substrate. Defects in the $\mathrm{Ni}_{3} \mathrm{P}$ were found to allow localised penetration of molten tin.

\section{Introduction}

Liquid solder interconnections for use in electronic assemblies exposed to high temperature environments have attracted much interest in recent years [1-3]. The major driving force behind this concept is that the use of a solder chosen such that it regularly becomes molten during normal operation of the equipment can prevent the build up of large thermal stresses in the solder joints and consequently the accumulation of damage due to the inelastic strains normally resulting from thermal cycling. A key issue in the practical implementation of this concept is to slow down the normally rapid interfacial reactions between the molten solder and the component and substrate metallization layers [3]. This may be partly achieved by applying a barrier layer of electroless $\mathrm{Ni}-\mathrm{P}$ onto these metallizations, as it is well known that electroless $\mathrm{Ni}-\mathrm{P}$ has a relatively slow reaction rate with solders compared with other common termination materials such as copper.

The interfacial reaction between electroless Ni-P alloys and liquid solders during reflow has been the focus of many studies [4-9]. However, the details of the reaction mechanism are still far from clear, as the presence of $P$ complicates the situation. It is generally found that apart from the formation of $\mathrm{Ni}_{3} \mathrm{Sn}_{4}$ intermetallic compounds (IMC) at the interface, a layer of $\mathrm{Ni}_{3} \mathrm{P}$ phase from the solder reaction-assisted crystallisation of amorphous Ni-P also precipitates adjacent to the IMC [8]. Whether the $\mathrm{Ni}_{3} \mathrm{P}$ phase thus formed is stable, and what the effect of its precipitation is on the continuing growth of $\mathrm{Ni}_{3} \mathrm{Sn}_{4}$, are still in doubt. It has been proposed that $\mathrm{Ni}_{3} \mathrm{P}$ may decompose to supply $\mathrm{Ni}$ atoms for the growth of $\mathrm{Ni}_{3} \mathrm{Sn}_{4}$ and that the ejected $\mathrm{P}$ atoms then diffuse back towards the $\mathrm{Ni}-\mathrm{P}$ to form $\mathrm{Ni}_{3} \mathrm{P}$ [4,6-8]. However, He et al. [5] ruled out the possibility of $\mathrm{Ni}_{3} \mathrm{P}$ 
decomposition based on an analysis of the destination of decomposed $\mathrm{P}$ atoms. They also claimed that the formation of $\mathrm{Ni}_{3} \mathrm{P}$ promoted the diffusion of $\mathrm{Ni}$ atoms and accounted for the faster growth of $\mathrm{Ni}_{3} \mathrm{Sn}_{4}$ IMCs on electroless $\mathrm{Ni}-\mathrm{P}$ than on pure $\mathrm{Ni}$, by releasing the reaction heat as well as providing rapid paths for diffusion due to their fine columnar microstructure. However, Hung et al. $[6,7]$ reported that $\mathrm{Ni}_{3} \mathrm{P}$ can act as a barrier layer for $\mathrm{Ni}$ diffusion and consequently suppresses the growth of $\mathrm{Ni}_{3} \mathrm{Sn}_{4}$, which in turn leads to the cessation of $\mathrm{Ni}_{3} \mathrm{P}$ growth.

The major conflict between the proposed explanations described above [4-9] for the liquid state interfacial reaction is centred around the stability of the $\mathrm{Ni}_{3} \mathrm{P}$ phase, which is difficult to evaluate due to the fact that during the reaction the formation and the potential decomposition of $\mathrm{Ni}_{3} \mathrm{P}$ phase are two simultaneous processes. The latter process, which takes place at the interface between the $\mathrm{Ni}_{3} \mathrm{P}$ and IMC or molten solder, provides the $\mathrm{P}$ atoms needed for the formation of new $\mathrm{Ni}_{3} \mathrm{P}$ phase at the interface next to the unreacted Ni-P $[4,6-8]$. Under such circumstances, samples with $\mathrm{Ni}_{3} \mathrm{P}$ phase already precipitated prior to the interfacial reaction, could provide more insight into the stability of $\mathrm{Ni}_{3} \mathrm{P}$ during the interfacial reaction, since interference from the simultaneous formation of $\mathrm{Ni}_{3} \mathrm{P}$ does not exist.

In this paper, electroless Ni-P coatings were deposited onto thin copper wires and heattreated at $500^{\circ} \mathrm{C}$ for 2 hours before being dipped into a pure molten tin bath. The purpose of the heat-treatment was to transform the amorphous Ni-P into the equilibrium state, which consists of crystallized $\mathrm{Ni}$ and $\mathrm{Ni}_{3} \mathrm{P}$, so that the reaction-assisted crystallisation of $\mathrm{Ni}_{3} \mathrm{P}$ during the solder reaction may be avoided and therefore any interference from its heat of formation and finegrained microstructure will not exist. By comparing the solder reaction behaviours of the Ni-P coatings in the as-plated and heat-treated conditions, the stability of $\mathrm{Ni}_{3} \mathrm{P}$ and its effects on the solder reaction were investigated. 


\section{Experimental procedures}

The pioneering study of liquid solder joints by Nowottnick et al. [2], used copper wires with a diameter of $2 \mathrm{~mm}$ to perform the dipping experiment. Following their work, all of the electroless Ni-P coatings used in this study were deposited onto thin copper wires (250 $\mu \mathrm{m}$ in diameter) to a thickness of approximately $15 \mu \mathrm{m}$. The choice of such thin copper wires as the substrate material was to avoid any significant change in the composition of the solder bath from the potential dissolution of the copper during the dipping experiment. The composition of the Ni-P coatings and the corresponding deposition conditions are given in Table 1.

The heat-treatment of the as-plated electroless Ni-P coatings was carried out under the protection of a flowing gas mixture of $\mathrm{N}_{2}$ and $5 \% \mathrm{H}_{2}$ to avoid surface oxidation. The heattreatment furnace was heated at a rate of $5^{\circ} \mathrm{C} / \mathrm{min}$ to $500^{\circ} \mathrm{C}$ and was held at that temperature for 2 hours to enable the precipitation of $\mathrm{Ni}_{3} \mathrm{P}$ and its growth into coarse grains. The furnace was then cooled down at $5^{\circ} \mathrm{C} / \mathrm{min}$ to room temperature. The precipitation of $\mathrm{Ni}_{3} \mathrm{P}$ and the resulting formation of a two-phased microstructure of well-crystallized $\mathrm{Ni}$ and $\mathrm{Ni}_{3} \mathrm{P}$ in heat-treated $\mathrm{Ni}-\mathrm{P}$ was confirmed by X-ray diffraction analysis. There was also a concern that the $P$ atoms in the coating may diffuse into the substrate during the heat-treatment [10], leading to a reduction of $P$ content in the coating. However, a compositional analysis indicated that the change in the $\mathrm{P}$ content in Ni-P coatings after heat-treatment was negligible.

The reaction of the Ni-P coatings with molten tin was studied by dipping the coated wires into molten tin (250 g, 99.96 wt\% purity) held in a ceramic crucible. Pure tin was used as it is the major constituent of most solder alloys likely to be used in the applications envisioned for liquid solder joint technology and, due to its high reactivity, is generally the component which takes part 
in the interfacial reactions. The reaction temperature was 250 or $290^{\circ} \mathrm{C}$, whilst the reaction time was 3-28 min. The immersion depth of the samples was about $15 \mathrm{~mm}$. Before dipping, all samples were coated in a strong flux (ACTIEC 5). Upon completion of the reaction step, the samples were withdrawn slowly from the solder bath.

Following dipping, the samples were mounted in electrically conductive resins and were metallographically polished for microstructural characterization and compositional analysis. These were carried out using a field emission gun scanning electron microscope (FEG-SEM) equipped with energy-dispersive X-ray spectroscopy (EDS). The thickness measurements of the different phases at the reaction interface were performed at a randomly chosen location on the circumference of cross-sections, such as that shown in Fig. 1a. For cross-sections such as shown in Fig. 1b, the measurement was done along the short axis of the ellipse, where the distortion of thickness is the least due to an oblique section plane.

\section{Results}

\subsection{Interface morphology}

Figure 2 shows the interfacial microstructure of the coating with $14 \mathrm{wt} \% \mathrm{P}$ in the as-plated and heat-treated states after the solder dipping experiment. For the as-plated samples, the interface shown in Fig. 2a exhibited a multilayered microstructure as typically observed for other solder/metallization combinations [4-9]. The dark layer adjacent to the remaining un-reacted Ni-P coatings was found by compositional analysis to consist of $\mathrm{Ni}$ and $\mathrm{P}$. The $\mathrm{P}$ content of this dark layer is about 17 wt.\%, which is very close to the stoichiometry of the $\mathrm{Ni}_{3} \mathrm{P}$ phase (15 wt\% P). Therefore, considering the solubility of $\mathrm{P}$ in $\mathrm{Ni}_{3} \mathrm{P}$, this dark layer is attributed to be the $\mathrm{Ni}_{3} \mathrm{P}$ phase, as identified in previous investigations $[4,8]$. The light grey layer next to the $\mathrm{Ni}_{3} \mathrm{P}$ was expected to be the $\mathrm{Ni}_{3} \mathrm{Sn}_{4}$ IMC. However, the compositional analysis as shown in Fig. 2c 
indicated that it consisted of $\mathrm{Ni}, \mathrm{Sn}$ and $\mathrm{P}$. For the heat-treated samples (as shown in Fig. 2b), a dark layer of $\mathrm{Ni}_{3} \mathrm{P}$ also formed at the interface after the dipping experiment, although its thickness was less than that shown in Fig. 2a.

The interfacial microstructure for Ni-P coatings with low/medium $\mathrm{P}$ contents after solder dipping for 12 minutes is shown in Fig 3. These interfaces showed a similar multilayered structure to those on samples with $14 \mathrm{wt} \% \mathrm{P}$. For these coatings, the $\mathrm{P}$ content in the dark layer next to the unreacted Ni-P was found to be approximately $15 \mathrm{wt} \%$. This dark layer was therefore treated as $\mathrm{Ni}_{3} \mathrm{P}$. From the comparison of the interfacial microstructure of samples with and without a heat-treatment prior to the dipping experiment, the decrease in the thickness of $\mathrm{Ni}_{3} \mathrm{P}$ formed on heat-treated samples is also apparent. Note that for the coating with $2 \mathrm{wt} \% \mathrm{P}$ in the heat-treated state, no $\mathrm{Ni}_{3} \mathrm{P}$ was observed to form at the interface during its reaction with molten tin (Fig. 3d).

Another characteristic of the interfacial microstructure of these Ni-P coatings after the dipping experiment is that for those which have a $\mathrm{P}$ content less than $11 \mathrm{wt} \%$, no matter whether they were subjected to a prior heat-treatment or not, they suffered from localised penetration of molten tin along certain paths (as can be seen from Fig. 3a). Under higher magnifications, it was found that the preferential penetration occurred at the boundaries where two Ni-P nodules meet (Fig. 4a). Such boundaries may also be responsible for the formation of cracks or channels $[6,9]$ in the $\mathrm{Ni}_{3} \mathrm{P}$ layer formed during the liquid solder reaction. As shown in Fig. 4b, a boundary was found underneath the location where the continuity of the $\mathrm{Ni}_{3} \mathrm{P}$ was interrupted.

\subsection{Characterisation of $\mathrm{Ni}_{3} \mathrm{P}$ growth}


Figure 5 shows the thickness of $\mathrm{Ni}_{3} \mathrm{P}$ formed during the solder reaction with different $\mathrm{Ni}-\mathrm{P}$ coatings at $290^{\circ} \mathrm{C}$ for 7 minutes. For the as-plated coatings, the $\mathrm{Ni}_{3} \mathrm{P}$ thickness increased with increasing $\mathrm{P}$ content until about 8 wt\%. A further increase in P content in the deposit did not lead to a further increase in the thickness of the $\mathrm{Ni}_{3} \mathrm{P}$ phase. For the heat-treated samples, no $\mathrm{Ni}_{3} \mathrm{P}$ phase was observed until the $\mathrm{P}$ content in the deposit was higher than about $6 \mathrm{wt} \%$. After that a similar increasing trend of $\mathrm{Ni}_{3} \mathrm{P}$ thickness with $\mathrm{P}$ content in the coating was observed, although the thickness of $\mathrm{Ni}_{3} \mathrm{P}$ was apparently less than that formed on as-plated samples.

It was found that the reaction rate between the electroless coatings and the molten tin at 290 ${ }^{\circ} \mathrm{C}$ was too fast to enable time dependent measurements. The whole coating (approximately 15 $\mu \mathrm{m}$ thick), and even the whole copper wire for most of the samples prepared in this study, were completely dissolved into the molten tin bath in less than 15 minutes. The reaction temperature was therefore reduced to $250^{\circ} \mathrm{C}$ in the following studies, which took place using a fresh molten tin bath. The variation with the reaction time of the thickness of $\mathrm{Ni}_{3} \mathrm{P}$ formed during the reaction at this temperature is shown in Fig. 6. Except for the heat-treated low $P$ coatings, where no $\mathrm{Ni}_{3} \mathrm{P}$ was observed, the thickness of $\mathrm{Ni}_{3} \mathrm{P}$ on all the other coatings increased rapidly at the beginning of the reaction. With increasing reaction time, the growth rate slowed down and eventually there was no significant further increase in the $\mathrm{Ni}_{3} \mathrm{P}$ thickness.

\subsection{Consumption rate of electroless Ni-P}

The thickness of the Ni-P coatings consumed during the reaction, defined as the thickness difference between the original Ni-P coating and the un-reacted Ni-P coating left underneath the $\mathrm{Ni}_{3} \mathrm{P}$ layer formed during the dipping experiment, is shown in Fig. 7. It can be seen that for the low $\mathrm{P}$ coatings, they appeared to be more reactive with molten tin in the heat-treated state than in the as-plated state. For the medium and high $\mathrm{P}$ coatings, their thickness consumed was found 
to be linearly proportional to the reaction time, but independent of their heat-treatment history. Meanwhile, there was no significant difference between the coatings with medium and high $\mathrm{P}$ contents, in the thickness of Ni-P consumed.

\subsection{Loss of $P$ into molten tin}

From the compositional analysis, it was found that some $\mathrm{P}$ was lost into the molten tin bath. However, in order to quantify the $\mathrm{P}$ loss, it is necessary to know the thickness of $\mathrm{Ni}_{3} \mathrm{P}$ under the ideal condition of mass conservation, when all the $\mathrm{P}$ ejected from the interfacial reaction between $\mathrm{Ni}-\mathrm{P}$ and molten tin is used for the formation of $\mathrm{Ni}_{3} \mathrm{P}$. As illustrated in Fig. 8, it is assumed that an electroless Ni-P coating with an original thickness of $t_{0}$, either on a planar substrate (Fig. 8a) or on a cylindrical substrate (Fig. 8b, and $2 r>>t_{0}$ ), has reacted with molten tin, forming a layer of IMC and $\mathrm{Ni}_{3} \mathrm{P}$ at the interface. The thickness of $\mathrm{Ni}_{3} \mathrm{P}$ is $t_{\mathrm{Ni}_{3} \mathrm{P}}$, while the thickness of the remaining unreacted Ni-P is $t_{\mathrm{Ni}-\mathrm{P}}$. The thickness of Ni-P consumed during the interfacial reaction is $t_{1}$, and $t_{1}+t_{N i-P}=t_{0}$. For a conservative reaction, the mass of $\mathrm{P}$ in the Ni-P coating consumed should be equal to that contained in the $\mathrm{Ni}_{3} \mathrm{P}$ phase formed. Therefore for a sample with a unit surface area, the following equation results:

$$
t_{1} \rho_{\mathrm{Ni}-\mathrm{P}} C_{\mathrm{Ni}-\mathrm{P}}=t_{\mathrm{Ni}_{3} \mathrm{P}} \rho_{\mathrm{Ni}_{3} \mathrm{P}} \mathrm{CNi}_{3} \mathrm{P}
$$

where $\rho_{\mathrm{Ni}-\mathrm{P}}$ and $\rho_{\mathrm{Ni}_{3} \mathrm{P}}$ are the density and $c_{\mathrm{Ni}_{-} \mathrm{P}}, C_{\mathrm{Ni}_{3} \mathrm{P}}$ are the weight percentage of $\mathrm{P}$ in the Ni-P coating and the $\mathrm{Ni}_{3} \mathrm{P}$ phase, respectively. Rearranging Equation (1), the following relationship between the thickness of $\mathrm{Ni}-\mathrm{P}$ coating consumed $\left(t_{1}\right)$ and the thickness of $\mathrm{Ni}_{3} \mathrm{P}$ phase formed $\left(t_{N_{3} P}\right)$ is obtained:

$$
\frac{t_{N_{3} P}}{t_{1}}=\frac{t_{N_{3} P}}{t_{0}-t_{N i-P}}=\frac{\rho_{N i-P} C_{N i-P}}{\rho_{N_{3} P} C_{N i_{3} P}}
$$


The density of Ni-P coating $\rho_{\mathrm{Ni}-\mathrm{P}}$ in Equation (2) can be calculated from the empirical equation $[10,11]:$

$$
\rho_{N i-P}=\frac{113.6-c_{N i-P}}{12.7} \quad\left(\text { valid if } c_{N i-P}<13 \%\right)
$$

Since $\rho_{\mathrm{Ni}_{3} \mathrm{P}}=7.823 \mathrm{~g} / \mathrm{cm}^{3}$ and $c_{\mathrm{Ni}_{3} \mathrm{P}}=15 \%$, Equation (2) indicates that for a Ni-P coating with a known P content $c_{N i-P}$, the thickness ratio $\frac{t_{N_{3} P}}{t_{1}}$ is a constant. So

$$
t_{N_{3} P}=k t_{1}=k\left(t_{0}-t_{N i-P}\right), \quad k=\frac{\rho_{N i-P} C_{N i-P}}{\rho_{N_{i} P} C_{N_{3} P}}
$$

Normalising thicknesses $t_{1}, t_{\mathrm{Ni}_{3} \mathrm{P}}$ and $t_{\mathrm{Ni}-\mathrm{P}}$ to the original coating thickness $t_{0}$ so as to avoid interference from the variation of $t_{0}$ between different samples, one then obtains:

$$
t_{N_{3} P}^{*}=k\left(1-t_{N i-P}^{*}\right)
$$

Where $t_{N_{3} P}^{*}=\frac{t_{N_{3} P}}{t_{0}}, t_{N i-P}^{*}=\frac{t_{N i-P}}{t_{0}}$.

Figure 9 shows the normalised thickness of $\mathrm{Ni}_{3} \mathrm{P}$ phase $\left(t_{\mathrm{N}_{3} \mathrm{P}}^{*}\right)$ plotted against the normalised thickness of Ni-P coatings consumed $\left(1-t_{N i-P}^{*}\right)$ during the dipping experiment. The straight line is plotted from Equation 5, which gives the theoretical thickness of $\mathrm{Ni}_{3} \mathrm{P}$ when no loss of $\mathrm{P}$ occurs. It can be seen from Fig. 9 that during the earlier stages of the interfacial reaction (except for the heat-treated low $\mathrm{P}$ coating), the actual thickness of $\mathrm{Ni}_{3} \mathrm{P}$ measured is very close to the theoretical line, indicating that no or only a limited quantity of $\mathrm{P}$ is lost into the molten tin. However, as the reaction proceeds, the gap between the theoretical line and the experimental data point increases, which means that the loss of $\mathrm{P}$ during prolonged reaction increases.

\section{Discussion}

\subsection{Interface microstructure}


In this study, the interfaces formed as a result of the reaction between electroless Ni-P coatings and molten tin are characteristic of the following features:

(1) the presence of a continuous layer of $\mathrm{Ni}_{3} \mathrm{P}$ on both as-plated and heat-treated $\mathrm{Ni}-\mathrm{P}$ coatings (Fig 2 and Figs 3a, 3b);

(2) the loss of $\mathrm{P}$ to molten tin and the subsequent formation of a new layer consisting of $\mathrm{Ni}, \mathrm{Sn}$ and $\mathrm{P}$ (Figure 2);

(3) the absence of $\mathrm{a} \mathrm{Ni}_{3} \mathrm{Sn}_{4}$ layer, which can be observed on normal solder joints [4-9];

(4) the complete disappearance of $\mathrm{Ni}_{3} \mathrm{P}$ on heat-treated Ni-P with less than approximately 7 wt\% P (Figs 3c,3d, and Figs. 5,6);

(5) the localised penetration of $\mathrm{Ni}_{3} \mathrm{P}$ and its underlying Ni-P by molten tin (Fig. 4)

The presence of $\mathrm{Ni}_{3} \mathrm{P}$ on as-plated $\mathrm{Ni}-\mathrm{P}$ after its reaction with molten tin is not surprising. Many previous investigations on the interfacial reaction between $\mathrm{Ni}-\mathrm{P}$ and molten tin-based solders have observed a similar phenomenon. In view of the fact that, in as-plated Ni-P, P exists as an elemental solute in a Ni-based solid solution, Jang et al. [8] ascribed the formation of $\mathrm{Ni}_{3} \mathrm{P}$ to the selective reaction of $\mathrm{Ni}$ in $\mathrm{Ni}-\mathrm{P}$ with $\mathrm{Sn}$ in molten solders. As a consequence, $\mathrm{P}$ released from the selective reaction becomes enriched at the interface. The enrichment of $P$ eventually induces a recrystallisation reaction which leads to the formation of $\mathrm{Ni}_{3} \mathrm{P}$.

For heat-treated Ni-P, no previous studies have been made on its reaction with molten solders. The formation of a similar layer of $\mathrm{Ni}_{3} \mathrm{P}$ on heat-treated $\mathrm{Ni}-\mathrm{P}$ in this study was somewhat unexpected, since unlike the elemental $\mathrm{P}$ in as-plated $\mathrm{Ni}-\mathrm{P}$, the $\mathrm{P}$ in heat-treated Ni-P has already precipitated out as $\mathrm{Ni}_{3} \mathrm{P}$ prior to the reaction with molten tin. Heat-treated $\mathrm{Ni}-\mathrm{P}$ was microstructurally a two-phased mixture of $\mathrm{Ni}$ and $\mathrm{Ni}_{3} \mathrm{P}$, probably in a laminated format [11] (also see Fig. 4). Therefore, the formation of a single-phased layer of $\mathrm{Ni}_{3} \mathrm{P}$ on heat-treated $\mathrm{Ni}-\mathrm{P}$ 
seemed to indicate that the interfacial reaction was sustained by the outward diffusion of $\mathrm{Ni}$ atoms from the $\mathrm{Ni}$ phase, whilst the remaining $\mathrm{Ni}_{3} \mathrm{P}$ phase coalesced into a continuous layer. This reaction mechanism is similar to that proposed by He et al. [5] for as-plated Ni-P, although the $\mathrm{Ni}_{3} \mathrm{P}$ layer in the latter is formed by a recrystallisation reaction rather than a simple coalescing process.

Although It has been reported in the literature that some $\mathrm{P}$ had been lost into the molten solder $[6,9]$, no direct evidence of the existence of $P$ in phases other than $\mathrm{Ni}_{3} \mathrm{P}$ was provided. All the claims were in fact based on the thickness ratio of $\mathrm{Ni}_{3} \mathrm{P}$ and $\mathrm{Ni}_{3} \mathrm{Sn}_{4}$ phases [6]. Since $\mathrm{Ni}_{3} \mathrm{Sn}_{4}$ has a very irregular interface with solder [4-9], its thickness is difficult to measure accurately. In this study, the loss of $P$ was proved by the direct detection of $P$ in a Ni-Sn-P layer through the EDX analysis (Fig 2). As will be further explained later on, this loss was less likely due to the decomposition of $\mathrm{Ni}_{3} \mathrm{P}$. In contrast, it was believed that the enhanced mass transport of dissolving elements by our specific experimental setup was responsible for the loss of $P$ and thus the formation of Ni-Sn-P. In this work, very thin copper wires (approximately $250 \mu \mathrm{m}$ in diameter) were used as the substrate for the Ni-P plating samples, which were immersed in a large volume of molten tin for the interfacial reaction. It has been found that the mass transport rate of ions to and from a wire sample immersed vertically in a stationary electrolyte is inversely proportional to the third root of the wire radius [12]. The thinner the wire, the easier the mass transport. For the same reason of enhanced mass transport, $\mathrm{Ni}$ atoms dissolved from the reaction between $\mathrm{Ni}-\mathrm{P}$ and molten tin may diffuse into the bulk of the molten tin so easily that the concentration of $\mathrm{Ni}$ atoms at the interface cannot accumulate to the level required for the formation of $\mathrm{Ni}_{3} \mathrm{Sn}_{4} \mathrm{IMCs}$. This explains the absence of large $\mathrm{Ni}_{3} \mathrm{Sn}_{4}$ particles from our samples, although they have been observed in other studies of solder joints with planar substrates $[5,6,8]$. Without the protection from such a solid layer of $\mathrm{Ni}_{3} \mathrm{Sn}_{4}$, the $\mathrm{Ni}_{3} \mathrm{P}$ phase with a porous microstructure (with pores, or 
possibly Kirkendall voids $[5,8])$ was subjected to the direct attack of molten tin. This led to the penetration of tin along the microstructural defects, which would eventually cause the crumbling of $\mathrm{Ni}_{3} \mathrm{P}$ particles into the molten tin and the formation of a ternary layer of Ni-Sn-P.

In previous studies of the interfacial microstructure using TEM, a similar but much thinner (less than half a micron) ternary Ni-Sn-P alloy layer has also been identified in planar solder joints after solid state annealing $[8,14]$. The formation of such a Ni-Sn-P layer may also be due to the diffusion of $\mathrm{Sn}$ along the grain boundaries of $\mathrm{Ni}_{3} \mathrm{P}$, especially when all of the $\mathrm{Ni}-\mathrm{P}$ has been reacted and there is therefore an insufficient supply of $\mathrm{Ni}$ atoms from underneath the $\mathrm{Ni}_{3} \mathrm{P}$ to react with Sn from the solder [15].

In addition, the enhanced mass transport and the consequent absence of a layer of $\mathrm{Ni}_{3} \mathrm{Sn}_{4}$ IMC at the interface may also be responsible for the extreme reactivity of Ni-P observed in this study. For Ni-P on planar solder joints, an approximately $4 \mu \mathrm{m}$ thick layer of Ni-P was found to be able to survive in molten eutectic $\mathrm{Sn}-\mathrm{Bi}$ solder at $240{ }^{\circ} \mathrm{C}$ for about 48 hours before it failed by local penetration of liquid solder to the substrate [13]. However, it was found here that for Ni-P on thin wires, even a $15 \mu \mathrm{m}$ thickness can be totally dissolved into the molten tin at $250{ }^{\circ} \mathrm{C}$ in less than 30 mins.

The complete disappearance of $\mathrm{Ni}_{3} \mathrm{P}$ on heat-treated Ni-P with less than approximately $7 \mathrm{wt} \%$ $\mathrm{P}$ may be due to the small volume fraction of $\mathrm{Ni}_{3} \mathrm{P}$ in such low $\mathrm{P} \mathrm{Ni}-\mathrm{P}$ coatings. As a result, there was a large volume contraction as Ni atoms diffused out to react with $\mathrm{Sn}$ and therefore a large tensile stress induced in the coalesced $\mathrm{Ni}_{3} \mathrm{P}$. This tensile stress could enhance the penetration of molten tin along $\mathrm{Ni}_{3} \mathrm{P}$ boundaries, which may have caused the $\mathrm{Ni}_{3} \mathrm{P}$ particles to crumble into the molten tin. 


\section{2 $\mathrm{Ni}_{3} \mathrm{P}$ stability and its implications}

As described in Section 3.2.4, the loss of $\mathrm{P}$ mainly occurred after longer periods of reaction when the $\mathrm{Ni}_{3} \mathrm{P}$ became thicker. This result provides more support to the theory that during the interfacial reaction between electroless $\mathrm{Ni}-\mathrm{P}$ and molten solder, the $\mathrm{Ni}_{3} \mathrm{P}$ formed is stable and it does not decompose to release its $\mathrm{Ni}$ atoms [5]. The reason is that If $\mathrm{Ni}_{3} \mathrm{P}$ were not stable and it did decompose during the interfacial reaction, there would be a greater chance for $\mathrm{P}$ atoms from the decomposed $\mathrm{Ni}_{3} \mathrm{P}$ to diffuse into the molten tin (especially as, in this study, molten tin was in direct contact with $\mathrm{Ni}_{3} \mathrm{P}$ ), rather than to back diffuse through the solid $\mathrm{Ni}_{3} \mathrm{P}$ or $\mathrm{Ni}-\mathrm{P}$ phase. Although it has been proposed that the grain boundaries of fine $\mathrm{Ni}_{3} \mathrm{P}$ may provide a fast diffusion path $[4,8]$, the activation energy needed for the diffusion of $P$ atoms in the solid phase is still much higher than that in the liquid tin. Therefore the decomposition of $\mathrm{Ni}_{3} \mathrm{P}$ would mean a complete loss of $\mathrm{P}$ at any stage of reaction. Under the assumption of the decomposition of $\mathrm{Ni}_{3} \mathrm{P}$, it is difficult to explain the formation of $\mathrm{Ni}_{3} \mathrm{P}$ on both types of $\mathrm{Ni}-\mathrm{P}$ and no or limited loss of $\mathrm{P}$ at the early stage of reactions for as-plated Ni-P.

Although it is proposed that $\mathrm{Ni}_{3} \mathrm{P}$ does not decompose, this does not imply that $\mathrm{Ni}_{3} \mathrm{P}$ could form an effective barrier layer to protect the substrate from the attack of molten tin, which is of primary importance for the interfacial stability of liquid solder interconnections [3]. As can be seen from

Fig. 7, the consumption rate of Ni-P was linear for both types of Ni-P coatings with higher $\mathrm{P}$ contents. This implies that $\mathrm{Ni}$ atoms from the remaining $\mathrm{Ni}-\mathrm{P}$ underlying the $\mathrm{Ni}_{3} \mathrm{P}$ layer can diffuse through the $\mathrm{Ni}_{3} \mathrm{P}$ (up to a thickness of 2.0-2.5 $\mu \mathrm{m}$ ) without any difficulty. The consumption rate of $\mathrm{Ni}-\mathrm{P}$ was controlled by the chemical reaction of $\mathrm{Ni}$ and $\mathrm{Sn}$. On the other hand, the $\mathrm{Ni}_{3} \mathrm{P}$ formed, either by recrystallisation as for as-plated $\mathrm{Ni}-\mathrm{P}$ or by the coalescence of existing $\mathrm{Ni}_{3} \mathrm{P}$ particles, was not compact. The volume contraction and tensile stress developed during the 
formation of $\mathrm{Ni}_{3} \mathrm{P}$, as discussed in Section 4.1, may tear it apart at the original boundaries of $\mathrm{Ni}-\mathrm{P}$ nodules (Fig. 4), which is where these stresses concentrate. Such defects are believed to be the locations where the penetration of molten tin eventually started.

In order to improve the resistance of electroless Ni-P to the attack of molten tin and thus to maintain the interface stability of liquid solder interconnections, one possible approach is to introduce some high melting point elements into the coating, such as Cr, W and Mo [10,11]. As the coating reacts with molten solders, these elements get enriched at the surface. As a result, the diffusion of nickel atoms can be slowed down. Our recent work with electroless Ni-W-P alloys [16] has proved that the addition of $W$ can greatly extend the service life of the barrier metallization.

\section{Conclusions}

In this study, we compared the reaction characteristics of different electroless Ni-P coatings with molten tin. $\mathrm{Ni}_{3} \mathrm{P}$ was found to form on all as-plated Ni-P coatings. On heat-treated $\mathrm{Ni}-\mathrm{P}, \mathrm{Ni}_{3} \mathrm{P}$ was observed only when the $\mathrm{P}$ content in the coating was higher than approximately 7 wt\%. The thickness of $\mathrm{Ni}_{3} \mathrm{P}$ was thicker on as-plated Ni-P than on heat-treated samples. No $\mathrm{Ni}_{3} \mathrm{Sn}_{4}$ was observed in any of the samples. Instead a new layer consisting of $\mathrm{Ni}$, $\mathrm{Sn}$ and $\mathrm{P}$ was found, indicating the loss of $P$ to the molten tin side. The absence of $\mathrm{Ni}_{3} \mathrm{Sn}_{4}$ is explained by the enhanced mass transport of dissolved $\mathrm{Ni}$ atoms, while the loss of $\mathrm{P}$ is ascribed to the crumbling of $\mathrm{Ni}_{3} \mathrm{P}$ particles into the molten tin. A mass conservation analysis of $\mathrm{P}$ indicated that the loss of $P$ mainly occurred when $\mathrm{Ni}_{3} \mathrm{P}$ was thick. It is therefore proposed that, during the interfacial reaction, $\mathrm{Ni}_{3} \mathrm{P}$ is stable and doesn't undergo chemical decomposition. The only source of $\mathrm{Ni}$ for the reaction is therefore the outward diffusion of Ni from the unreacted Ni-P. On as-plated Ni-P coatings, $\mathrm{Ni}_{3} \mathrm{P}$ is formed by the enrichment of $\mathrm{P}$ and the consequently induced recrystallisation reaction; whist on heat-treated $\mathrm{Ni}-\mathrm{P}$ coatings, $\mathrm{Ni}_{3} \mathrm{P}$ is formed by the coalescence of already 
precipitated $\mathrm{Ni}_{3} \mathrm{P}$ particles due to the heat-treatment. However, $\mathrm{Ni}_{3} \mathrm{P}$ cannot form an effective barrier against the attack of molten tin, since $\mathrm{Ni}$ atoms from the unreacted Ni-P underneath can diffuse through it without any difficulty, resulting in a linear consumption rate of Ni-P. Meanwhile, the defects in $\mathrm{Ni}_{3} \mathrm{P}$ could also allow localised penetration of molten tin towards the substrate.

\section{Acknowledgements}

This research was funded by the Engineering and Physical Science Research Council (Grant Ref. GR/S87485/01) in collaboration with Dynex Semiconductor Ltd., TWI Ltd., Henkel Ltd. and Oxford Applied Technology Ltd.

[1] Keeler R. Electron Pack Prod 1989;29:14

[2] Nowottnick M, Pape U, Wittke K, Scheel W. SMTA International Conf. Proc., Chicago, IL, Sept. 21-25, 2003, p.693-699

[3] Mannan SH, Clode MP. IEEE Trans Adv Pack 2004;27:508

[4] Liu P, Xu Z, and Shang JK. Metall Mater Trans A 2000;31A:2857

[5] He M, Lau WH, Qi G, and Chen Z. Thin Solid Films 2004;462-463:376

[6] Hung KC, Chan YC, Tang CW, and Ong HC. J Mater Res 2000;15:2534

[7] Hung KC, Chan YC, Tang CW. J Mater Sci Mater-Mater El 2000;11:587

[8] Jang JW, Kim PG, Tu KN, Frear DR, Thompson P. J Appl Phys 1999;85:8456

[9] Hung KC, Chan YC. J Mater Sci Lett 2000;19:1755

[10] Gawrilov GG, Chemical (electroless) nickel-plating, Portcullis Press, Redhill, 1979. p. 98

[11] Riedel W, Electroless Nickel Plating, Finishing Publications, 1991. p.134

[12] Ibl N, Electrochim Acta 1959;1:3 
[13] Chen K, Li J, Liu C, Whalley DC, Hutt DA, Conway PP, Mannan SH, Clode MP, Lobato H. The International Conference of High Temperature Electronics (HITEN 2005), Paris, France. 6-8 Sept. 2005

[14] Vuorinen V, laurila T, Yu H, and Kivilahti JK. J Appl Phys 2006;99:023530

[15] Kumar A, Chen Z, Mhaisalka SG, Wong CC, Teo PS, and Kripesh V. Thin Solid Films $2006 ; 504: 410$

[16] Chen K, Liu C, Whalley, DC, Hutt, DA, Li, JF and Mannan, SH. Proceedings of the 1st IEEE Electronic Systemintegration Technology Conference, Dresden, Germany, September 2006, p. $421-427$ 
TABLE 1 Electrolytes and deposition conditions for the electroless Ni-P coatings

\begin{tabular}{lcccccccc}
\hline \hline \multirow{8}{*}{$\begin{array}{l}\text { Composition } \\
\text { and conditions }\end{array}$} & \multicolumn{8}{c}{ Formulation No. } \\
\cline { 2 - 8 } & $1^{*}$ & 2 & 3 & 4 & 5 & $6^{* *}$ & 7 & 8 \\
\hline $\begin{array}{l}\mathrm{NiSO}_{4} \cdot 6 \mathrm{H}_{2} \mathrm{O} \\
(\mathrm{g} / \mathrm{l})\end{array}$ & 40 & 40 & 40 & 26 & 26 & 24 & 30 & 26 \\
$\begin{array}{l}\mathrm{NaH}_{2} \mathrm{PO}_{2} \cdot \mathrm{H}_{2} \mathrm{O} \\
(\mathrm{g} / \mathrm{l})\end{array}$ & 11 & 11 & 11 & 16 & 16 & 24 & 14 & 16 \\
$\mathrm{pH}$ & 8.8 & 9.5 & 8.0 & 10.0 & 9.0 & 4.5 & 8.0 & 8.0 \\
$\begin{array}{l}\mathrm{Temperature} \\
\left({ }^{\circ} \mathrm{C}\right)\end{array}$ & 80 & 80 & 90 & 80 & 80 & 90 & 90 & 90 \\
$\begin{array}{l}\mathrm{P} \text { content } \\
\text { deposits } \\
\left({ }^{\dagger}\right.\end{array}$ & 2.0 & 3.8 & 5.0 & 6.5 & 7.5 & 10.0 & 13.0 & 14.0 \\
\hline \hline
\end{tabular}

* plus $0.6 \mathrm{mg} / \mathrm{l}$ thiourea

** plus $28 \mathrm{ml} / / \mathrm{l}$ lactic acid and $2.2 \mathrm{ml} / / \mathrm{l}$ propionic acid

${ }^{\dagger}$ the $\mathrm{P}$ contents are for as-plated samples

All formulations except $\mathrm{No} 6$ also contained $60 \mathrm{~g} / \mathrm{l} \mathrm{Na} 3 \mathrm{C}_{6} \mathrm{H}_{5} \mathrm{O}_{7} \cdot 2 \mathrm{H}_{2} \mathrm{O}, 66 \mathrm{~g} / \mathrm{l}\left(\mathrm{NH}_{4}\right)_{2} \mathrm{SO}_{4}$ 
FIG. 1. SEM micrographs showing the cross-sections obtained under different conditions: (a) section plane normal to the copper wire; (b) section plane not normal to the wire

FIG 2. The interfacial microstructure of Ni-P coatings with $14 \mathrm{wt} \% \mathrm{P}$ in the as-plated (a) and the heat-treated (b) conditions after a reaction with molten tin at $250^{\circ} \mathrm{C}$ for 12 minutes. (c) shows the line profiles of $\mathrm{Ni}, \mathrm{Sn}$ and $\mathrm{P}$ at the interface shown in (a)

FIG 3. Micrographs showing the interfacial microstructure of Ni-P coatings with low/medium $\mathrm{P}$ contents for different treatment conditions. (a) 7.5 wt\% P, as-plated; (b) $7.5 \mathrm{wt} \% \mathrm{P}$, heat-treated; (c) 2.0 wt $\%$ P, as-plated; (d) 2.0 wt $\%$ P, heat-treated

FIG 4. Micrographs showing (a) the local penetration of a heat-treated Ni-P coating (7.5 wt $\%$ P) by molten tin at Ni-P nodule boundaries and (b) the formation of cracks in $\mathrm{Ni}_{3} \mathrm{P}$ due to the boundary effect.

FIG 5. Effect of the $\mathrm{P}$ content in the deposit and the heat-treatment on the thickness of $\mathrm{Ni}_{3} \mathrm{P}$ formed at the interface

FIG 6. Variation of $\mathrm{Ni}_{3} \mathrm{P}$ thickness with reaction time for $\mathrm{Ni}-\mathrm{P}$ coatings with different $\mathrm{P}$ contents. (a) 2.0 wt $\%$ P, as-plated; (b) 2.0 wt $\%$ P, heat-treated; (c) 7.5 wt $\%$ P, as-plated; (d) 7.5 wt $\%$ P, heat-treated; (e) 14 wt\% P, as-plated; (f) 14 wt\% P, heat-treated 
FIG 7. The variation with reaction time in the thickness of Ni-P coatings consumed during the reaction at $250^{\circ} \mathrm{C}$.

FIG 8. Schematic illustration of the geometry of different phases at the interface of Ni-P on (a) planar substrates; (b) wire substrates with a diameter of $2 r$.

FIG 9. The relationship between the thickness of $\mathrm{Ni}-\mathrm{P}$ consumed and the thickness of $\mathrm{Ni}_{3} \mathrm{P}$ formed during the interfacial reaction. The straight lines represent the mass conservative reaction of $P$. The data points were measured on the cross-section of samples. 


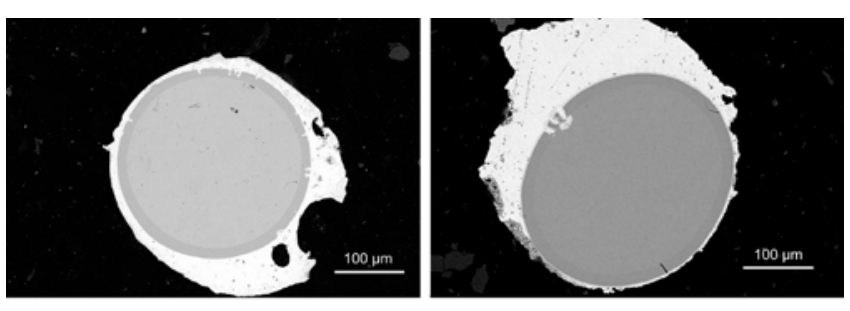

Figure 1

Fig 1

(a)

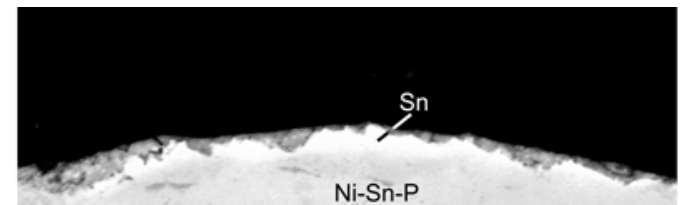

$\mathrm{Ni}_{3} \mathrm{P}$

$\mathrm{Ni}-\mathrm{P}$

Cu sbstrate

$10 \mu \mathrm{m}$

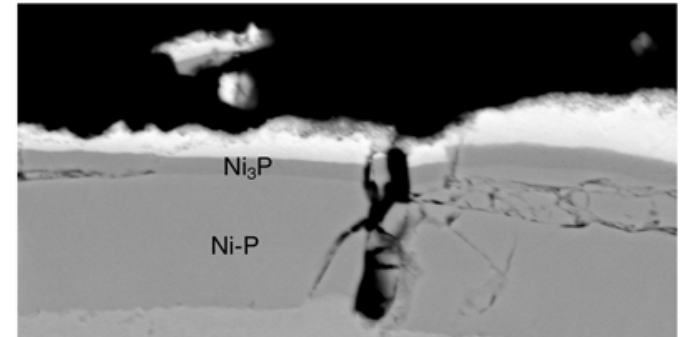

Cu substrate

$10 \mu \mathrm{m}$

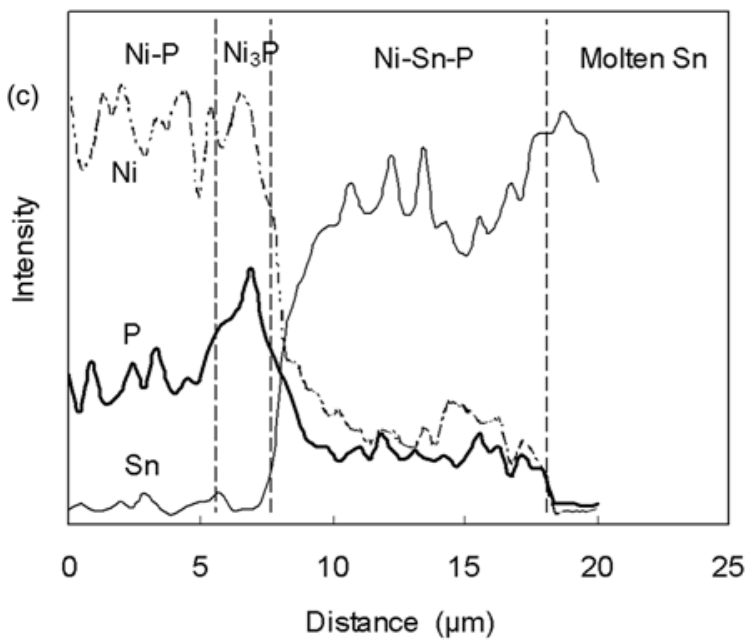

Fig 2 


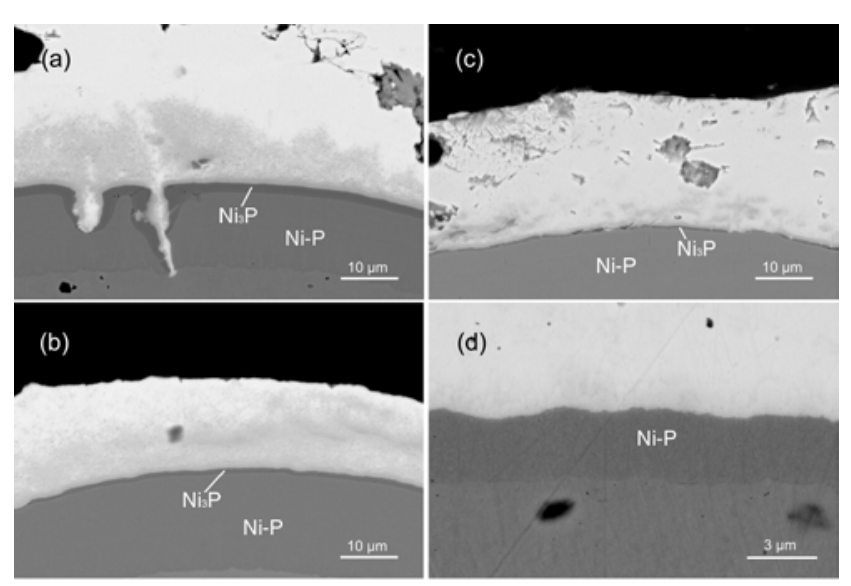

Fig 3

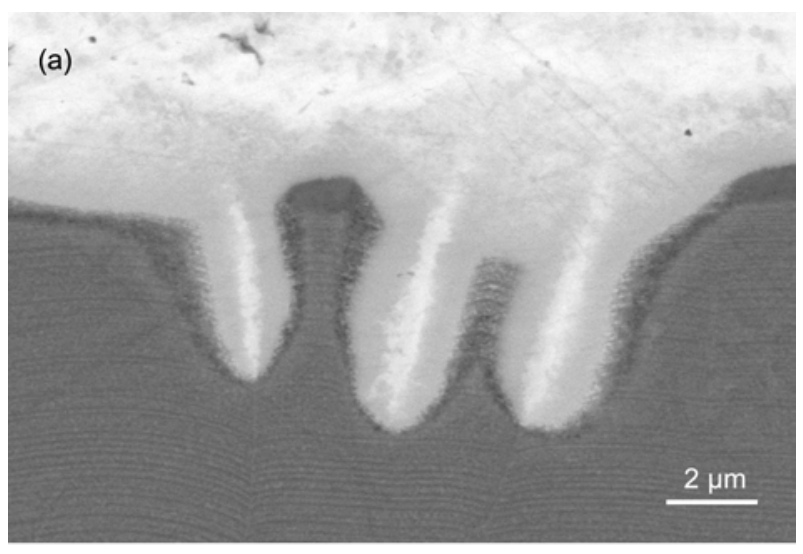

Fig 4a

(b)

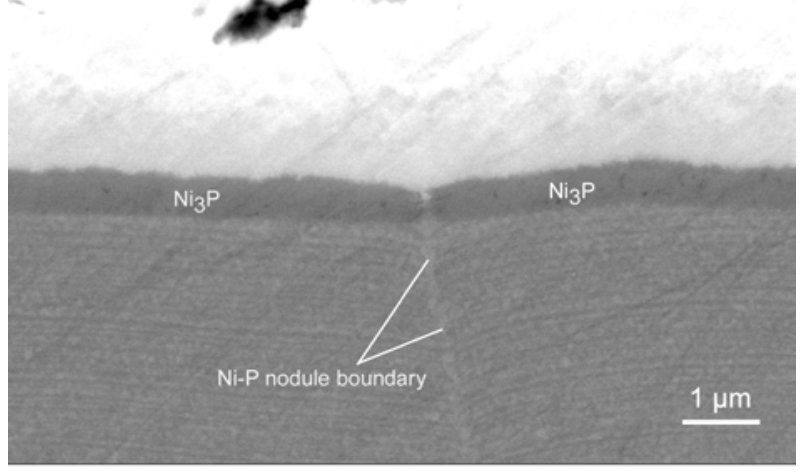

Fig 4b 


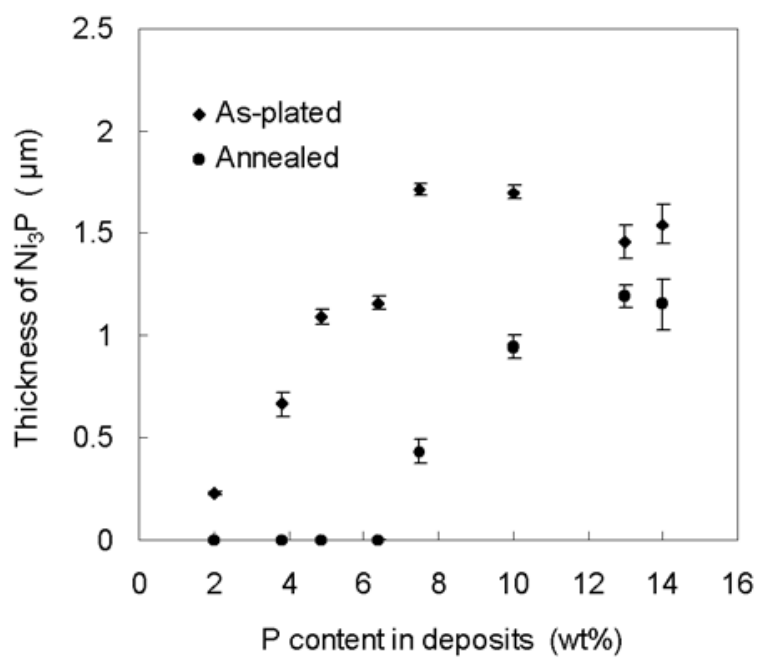

Fig 5

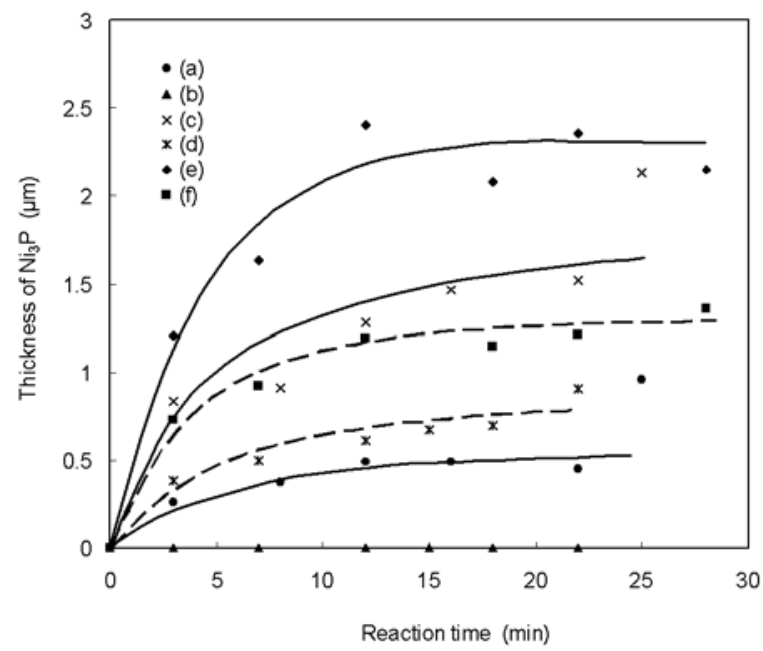

Fig 6 


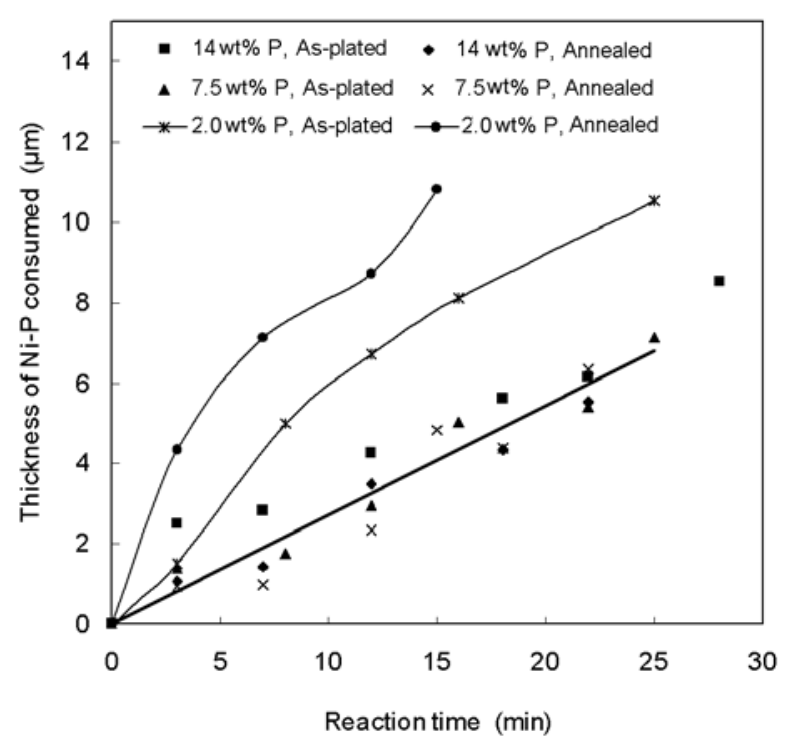

Fig 7

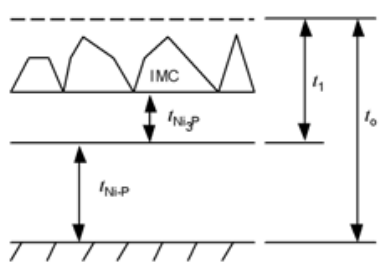

(a)

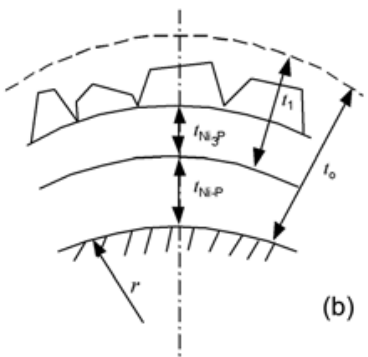

Fig 8 

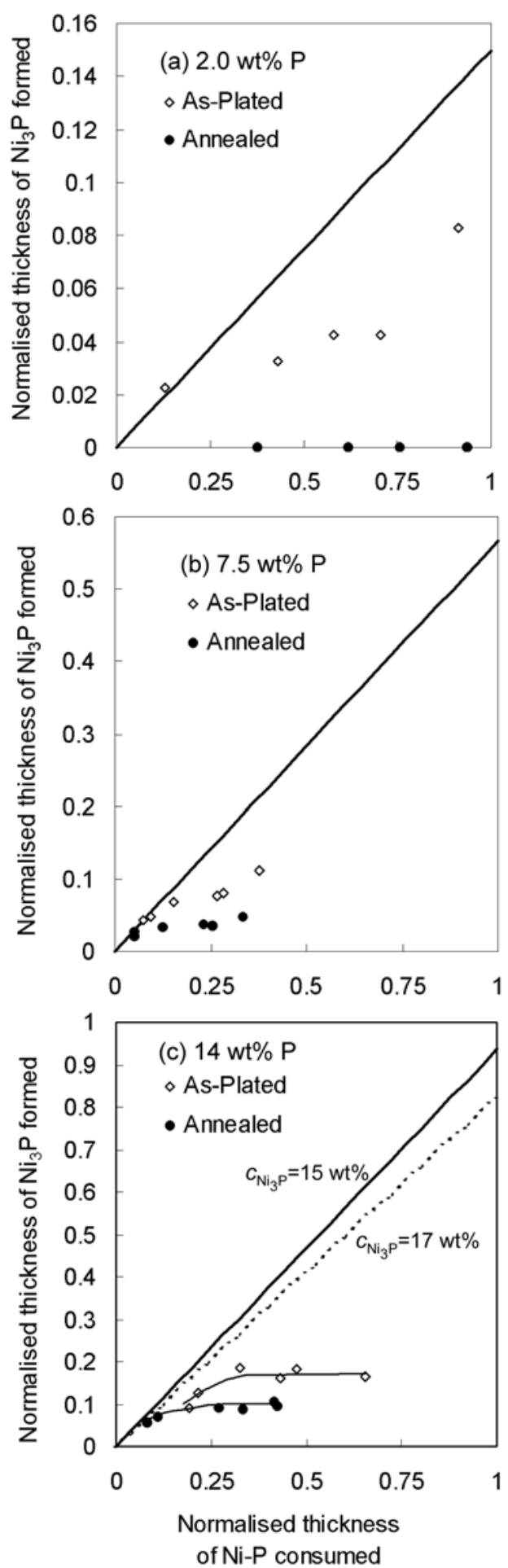

Fig 9 